\title{
Heitor Péres e a Praxiterapia Integral na Colônia Juliano Moreira
}

\author{
João Henrique Queiroz de Araújo* \\ Universidade do Estado do Rio de Janeiro - UERJ, Rio de Janeiro, RJ, Brasil \\ ORCID: https://orcid.org/0000-0002-5727-7989 \\ Ana Maria Jacó-Vilela** \\ Universidade do Estado do Rio de Janeiro - UERJ, Rio de Janeiro, RJ, Brasil \\ ORCID: https://orcid.org/0000-0002-0728-8700
}

\begin{abstract}
RESUMO
Neste artigo, realiza-se um estudo historiográfico sobre o psiquiatra Heitor Péres, quem, dentre outras funções assumidas no serviço público, dirigiu a Colônia Juliano Moreira entre 1946 e 1956. A pesquisa teve como interesse principal investigar suas contribuições na área da praxiterapia, isto é, o uso de ocupações terapêuticas no âmbito da assistência psiquiátrica. Heitor Péres foi um grande entusiasta do que denominou praxiterapia integral. Sua trajetória profissional auxilia a compreender o lugar desta prática no campo da medicina psiquiátrica no Rio de Janeiro. As conclusões deste estudo sugerem o emprego paralelo de teorias organicistas e métodos de tratamentos com base nas ocupações terapêuticas em sua prática profissional. A trajetória de Heitor Péres ajuda a problematizar a leitura histórica que se tem feito da psiquiatria brasileira das décadas de 1940 e 1950, assim como a desmistificar a ideia de que a praxiterapia era percebida neste contexto como um método de tratamento inferior àqueles de base organicista.
\end{abstract}

Palavras-chave: Heitor Péres, Colônia Juliano Moreira, praxiterapia, arteterapia.

\section{Heitor Péres and the Integral Praxitherapy at the Colônia Juliano Moreira}

\begin{abstract}
In this article, a historiographical study is performed about the psychiatrist Heitor Péres, who, among other functions assumed in the public service, directed the Colonia Juliano Moreira between 1946 and 1956. The research had as main interest to investigate the contributions of this character to praxitherapy, or the use of therapeutic occupations within psychiatric care. Heitor Péres was a great promoter and disseminator of what he called integral praxitherapy, in addition to art therapy. His professional career helps to understand the place of these practices in the psychiatric medicine field in Rio de Janeiro. The conclusions of this study suggest the parallel use of organicist theories and treatment methods based on therapeutic occupations in his professional practice. The trajectory of Heitor Péres helps to problematize the history of Brazilian psychiatry of the 1940s and 1950s, as well as to demystify the idea that praxitherapy was perceived in this context as a method of treatment inferior to those based on organicism.
\end{abstract}

Keywords: Heitor Péres, Colonia Juliano Moreira, praxitherapy, art therapy.

ISSN $1808-4281$ 


\section{Heitor Péres y la Praxiterapia Integral en la Colonia Juliano Moreira}

\section{RESUMEN}

En este artículo se realiza un estudio historiográfico sobre el psiquiatra Heitor Péres, quien, entre otras funciones asumidas en el servicio público, dirigió la Colonia Juliano Moreira entre 1946 y 1956. El estudio tuvo como principal interés investigar las contribuciones de este personaje a la praxiterapia, el uso de ocupaciones terapéuticas dentro de la atención psiquiátrica. Heitor Péres fue un gran promotor y difusor de lo que llamó praxiterapia integral, además de la terapia de arte. Su carrera profesional ayuda a comprender el lugar de esta práctica en el campo de la medicina psiquiátrica en Río de Janeiro. Las conclusiones de este estudio sugieren el uso paralelo de teorías organicistas y métodos de tratamiento basados en ocupaciones terapéuticas en su práctica profesional. La trayectoria de Heitor Péres ayuda a problematizar la lectura histórica que se ha hecho de la psiquiatría brasileña de los años 1940 y 1950, así como a desmitificar la idea de que a la praxiterapia se la percibía en este contexto como un método de tratamiento inferior a los basados en el organicismo.

Palabras-clave: Heitor Péres, Colonia Juliano Moreira, praxiterapia, terapia de arte.

Entre 1946 e 1956, o médico psiquiatra Heitor Carpinteiro Péres (1907-1990) dirigiu a Colônia Juliano Moreira (CJM), instituição psiquiátrica do Rio de Janeiro. Pouco conhecido pela historiografia, foi figura marcante no campo da psiquiatria por ter atuado em renomadas instituições psiquiátricas cariocas, além de ter participado de diversas entidades e associações médicas, assumindo, inclusive, postos de chefia em órgãos do Governo Federal. Sua biografia é aqui resgatada para fins de estudo sobre o uso das ocupações terapêuticas no tratamento de doentes mentais no Rio de Janeiro. Enquanto diretor da CJM, foi um grande entusiasta do uso da praxiterapia - como era denominada a terapia ocupacional na instituição - e chegou a formular um programa original de uso de ocupações com foco na coletividade: a praxiterapia integral.

Este artigo discute ainda o uso de atividades artísticas no interior da prática praxiterápica na CJM. Isto porque, durante a gestão de Heitor Péres foi criado um ateliê de pintura para os pacientes, a Colmeia de Pintores. Esta experiência foi desenvolvida na mesma época em que Nise da Silveira (1905-1999) assumiu a coordenação da Seção de Terapêutica Ocupacional (STO) do Centro Psiquiátrico Nacional (CPN), no Engenho de Dentro, também no Rio de Janeiro. No entanto, enquanto as atividades do ateliê de pintura e modelagem criado por Nise da Silveira na STO fizeram-na ganhar fama no Brasil e no exterior, a experiência da CJM encontra-se ainda praticamente desconhecida. 
Como não foram localizados trabalhos publicados sobre este personagem, esta pesquisa exigiu um levantamento de dados para construir sua biografia e trajetória profissional. Realizou-se, assim, consulta no arquivo da Academia Nacional de Medicina (ANM), onde foram localizados os documentos apresentados na ocasião de sua eleição para membro titular da instituição (currículo, monografia, parecer da comissão), ficha contendo dados pessoais, correspondências e transcrições de duas conferências proferidas por ele. Em um esforço de enriquecer a análise das informações contidas nestes documentos, foram realizadas também buscas na Hemeroteca Digital e no arquivo físico da Biblioteca Nacional, localizando-se 18 matérias de jornais que fazem referência à praxiterapia na CJM ou a Heitor Péres nas décadas de 1940 e 1950; íntegra de 10 artigos de sua autoria publicados em revistas científicas; e todos os números do periódico Boletim da Colônia Juliano Moreira, publicados com periodicidade irregular entre 1948 e 1954.

Para atender os objetivos desta pesquisa, as informações pessoais e dados profissionais de Heitor Péres foram organizados de forma a reconstruir sua trajetória profissional. A fim de compreender as contribuições deste personagem para o campo da praxiterapia em específico, foram analisados de forma mais sistemática os seus artigos e as matérias de jornais que tratam do uso de ocupações terapêuticas na CJM, assim como os números do Boletim da Colônia Juliano Moreira.

\section{Uma pequena biografia}

O médico psiquiatra Heitor Carpinteiro Péres nasceu em 3 de janeiro de 1907, na cidade de Cabo de Santo Agostinho, no Estado de Pernambuco. Passou parte de sua juventude no estado do Amazonas, onde seu pai era magistrado, e iniciou sua formação acadêmica em 1925, na Faculdade de Medicina e Cirurgia do Pará. Em 1927, solicitou transferência para a Faculdade de Medicina do Rio de Janeiro, onde se graduou em 1930. Ao longo de sua carreira, trabalhou em reconhecidas instituições, ao lado de diversas figuras ilustres, como será visto a seguir.

Durante seu período de formação, atuou como interno no Pavilhão de Observações do Hospício Nacional de Alienados, onde era realizada a prática da Clínica Psiquiátrica, cátedra pertencente a Henrique Roxo (1877-1969). Ainda na década de 1930, trabalhou na Policlínica de Botafogo e na Policlínica de Copacabana, duas conhecidas instituições privadas. Na primeira, foi chefe do Serviço de Psiquiatria e Higiene Mental. Já na Policlínica de 
Copacabana, não só chefiou a Clínica Psiquiátrica como também foi secretário da direção entre os anos de 1933 e 1935.

Sua carreira incluiu ainda significativa atuação no magistério. Em 1934, assumiu o cargo de livre docente da Universidade do Brasil, por meio de concurso. Foi também professor de Legislação Social da Escola de Enfermagem Alfredo Pinto entre 1938 e 1942, professor de Legislação do curso de Psiquiatria Clínica e Higiene Mental do Departamento Nacional de Saúde entre 1939 e 1942 e professor do Departamento de Psiquiatria e Psicanálise da Escola de Pós-Graduação Médica Carlos Chagas, no ano de 1953.

Paralelamente à carreira docente, em 1933, após concurso, tomou posse como psiquiatra do Serviço Nacional de Doenças Mentais (SNDM), sendo lotado na CJM. Entre os anos de 1937 e 1941, assumiu as funções de assistente técnico e diretor substituto da Divisão de Assistência a Psicopatas (DAP) do Ministério da Educação e Saúde. Fundou, em 1941, a Seção de Cooperação do SNDM, a qual dirigiu até 1946. Neste mesmo ano, assumiu a direção da CJM, permanecendo no cargo até 1956, período em que buscou implementar um método de tratamento e ressocialização que denominou praxiterapia integral.

Em 1957, foi eleito membro titular da ANM, assumindo a cadeira do antecessor, Adauto Botelho (1895-1963), o criador do SNDM. Na entidade, exerceu a função de $1^{\circ}$ secretário de 1961 a 1963. Em 1985, foi alçado ao grau de membro emérito.

Heitor Péres faleceu em 10 de agosto de 1990. Hoje, o psiquiatra empresta seu nome ao prédio da administração do atual Instituto Municipal de Assistência à Saúde Juliano Moreira (IMASJM).

\section{O lugar da praxiterapia na produção científica de Heitor Péres}

A produção científica de Heitor Péres, situada entre as décadas de 1930 e 1970, mostra-se bastante eclética, apesar de ser possível identificar em seus artigos alusões claras às questões que guiaram a psiquiatria neste período. Seus trabalhos publicados em periódicos tratam, em sua maioria, de aspectos etiológicos das doenças mentais e formas de tratamento das toxicomanias, além de propostas organizacionais e arquitetônicas para a assistência, que buscavam afirmar o caráter científico das instituições psiquiátricas. Como é de se esperar de um homem de sua época, grande parte dos artigos publicados por Heitor Péres refletem a tendência organicista da psiquiatria brasileira. Porém, isto não significa dizer que este tenha sido seu único ponto de vista para compreender e tratar as doenças mentais. 
Por outro caminho, interessou-se também pela praxiterapia, forma de tratamento por meio do trabalho e outras ocupações. Ainda nesta área, manifestou interesse pela arteterapia, prática já bastante conhecida na historiografia da psiquiatria pelos estudos sobre o trabalho realizado por Osório César (1895-1979), no Hospício do Juquery, em São Paulo, e por Nise da Silveira, no CPN, no Rio de Janeiro. O fato de ter publicado poucos textos sobre estes temas, associado à pluralidade de interesses que desenvolveu ao longo de sua carreira, pode ter contribuído para que seus aportes para a área da praxiterapia e arteterapia tenham passado despercebidos pelos historiadores das práticas e saberes psi no Brasil. Por essa razão, este estudo busca situar seu trabalho e produção neste contexto, resgatando suas descobertas e subsídios a esta atividade.

A primeira publicação de Heitor Péres, intitulada Formas mentais da encefalite letárgica, data de 1930 (Mathias, 2017). Porém, o dossiê de Heitor Péres na ANM não faz menção a este trabalho. Isto posto, existe a possibilidade deste ser o título de sua tese de doutoramento, defendida no mesmo ano. Como seu trabalho de conclusão de curso não aparece no Catálogo de Teses da Faculdade de Medicina do Rio de Janeiro, esta informação não pôde ser confirmada até o momento.

De acordo com o currículo apresentado para sua eleição para membro titular da ANM, em 1957, Heitor Péres teria publicado até então 46 artigos em revistas brasileiras e 7 no exterior, além de ter 22 conferências, aulas, discursos e ensaios publicados em revistas. Apenas como exemplo destes artigos, tem-se o trabalho Da esquizofrenia. Formas clinicas. Ensaio de revisão da casuistica nacional, publicado em 1931 nos Anais da Assistência a Psicopatas, escrito em parceria com Ignácio da Cunha Lopes (1891-1973). No mesmo ano, foi publicado na Revista das Clínicas o artigo Psicoses periódicas tardias. Em 1934, Heitor Péres teve um capítulo intitulado A Esquizofrenia latente e sua importância médico-legal publicado no livro Novidades em doenças mentaes (sic), organizado por Henrique Roxo. Entre 1933 e 1935, publicou 4 artigos na revista Imprensa Médica, respectivamente intitulados Paralisia geral feminina, Esquizofrenia paranoide e mutismo, Encefalite letárgica e histeria e Epilepsia simulada. Escreveu ainda muitos outros artigos na mesma linha organicista ao longo de sua carreira.

Quanto aos seus textos que tratam especificamente das toxicomanias, publicou, a partir do ano de 1937, os seguintes trabalhos: Diambismo (1937), na revista Ilustração Médica; Benzedrinismo (1940), na revista Cultura Médica; Alcoolismo e educação, na revista Arquivos Brasileiros de Higiene Mental; Educação Anti-alcoólica (1949), no Boletim da Colônia Juliano Moreira; A narcose tio-barbitúrica, como método de toxiprivação (1949), no 
Boletim da Colônia Juliano Moreira; e Alcoolismo da mulher (1960), no Jornal Brasileiro de Medicina. Além destes artigos, apresentou a monografia Alguns aspectos sócio-psiquiátricos do canabismo brasileiro para eleição como membro titular da ANM. Já na década de 1970, proferiu durante um curso as conferências Legislação brasileira anti-drogras e Toxicomania e adolescência, cujas transcrições encontram-se no arquivo ANM.

É preciso mencionar que Heitor Péres foi membro da Liga Brasileira de Higiene Mental (LBHM), entidade fundada em 1923 com o objetivo de aprimorar os serviços psiquiátricos e promover a profilaxia das doenças mentais. A partir do final da década de 1920, a LBHM assumiu um discurso eugênico com vistas ao "melhoramento" da raça (Costa, 2006). Dentre as grandes preocupações dos higienistas brasileiros neste momento estava o alcoolismo, considerado um dos principais problemas da degeneração racial. Os membros da LBHM acreditavam que o consumo de determinadas substâncias tóxicas, especialmente o álcool, predispunha os sujeitos e seus descendentes à loucura e à criminalidade.

Heitor Péres publicou também, como mencionado, alguns artigos sobre formas de organização e aspectos arquitetônicos dos serviços psiquiátricos. Entre eles estão: $A$ assistência psiquiátrica em Minas Gerais (1940), Novo sistema de janelas para hospitais psiquiátricos (1946), Hospital pequeno, ambulatório grande (1946), publicados na revista Cultura Médica; Janela conversível: fator de humanização dos hospitais psiquiátricos (1949) e Clínicas psiquiátricas urbanas (1950), publicados no Boletim da Colônia Juliano Moreira; e Normas para racionalização dos serviços psiquiátricos (1955), publicado na Revista Brasileira de Saúde Mental.

Por fim, dos temas que estão presentes em sua produção, a praxiterapia aparece em dois artigos, um de 1938, intitulado Terapêtica ocupacional, publicado na revista Arquivos Brasileiros de Medicina, e outro de 1949, intitulado Praxiterapia Integral, publicado no Boletim da Colônia Juliano Moreira. Embora possua apenas dois textos sobre este assunto, cabe pontuar que o Boletim da Colônia Juliano Moreira (publicado na época em que Heitor Péres era diretor da CJM) promoveu a praxiterapia ao apresentar artigos sobre o assunto ou por meio da divulgação de atividades afins realizadas na própria instituição. Neste sentido, este periódico foi uma importante fonte para nossa pesquisa.

Apesar da ênfase dada às teorias organicistas na maior parte de seus artigos, Heitor Péres também levava em consideração aspectos psicodinâmicos e sociais na compreensão e tratamento das doenças mentais. Em Narrativas de um psiquiatra (1950), seu único livro publicado, suas análises psicodinâmicas - e não explicações embasadas em teorias organicistas - destacam-se nos curiosos casos de pacientes apresentados ao leitor. Apoiando- 
se em sua experiência profissional, ele ratifica ainda a importância da praxiterapia no campo da assistência psiquiátrica. Segundo Péres (1950a) este seria "o mais racional dos métodos de cura", pois "conduz muitos enfermos à recuperação completa e, nos incuráveis evita a deterioração, a decadência psíquica, normalizando o ambiente" (Péres, 1950a, p. 92).

Este tipo de afirmação, que Heitor Péres fez também em outras oportunidades, despertou o interesse por sua atuação no desenvolvimento da praxiterapia na CJM e na divulgação desta forma de tratamento das doenças mentais no Brasil. Isto porque existe um entendimento de que a psiquiatria brasileira das décadas de 1940 e 1950 tenderia hegemonicamente à lógica organicista, especialmente quando colocada em contraponto à história da praxiterapia e ao uso de atividades artísticas em instituições psiquiátricas.

Nise da Silveira, um dos mais conhecidos nomes destes campos, chegou a afirmar em seu livro O mundo das imagens, de 1992, que, diante dos modernos tratamentos organicistas utilizados na época em que criou a STO, em 1946, seu método foi considerado "ingênuo e quase inócuo" pela psiquiatria de seu tempo (Silveira, 1992, p. 16). Esta afirmação, assimilada de forma descontextualizada, pode contribuir para a produção de uma visão homogeneizante da história da psiquiatria brasileira. Com base neste tipo de discurso, alguns autores costumam reproduzir, por exemplo, a ideia de que as ocupações terapêuticas e a arteterapia possuíam, neste período, posição subalterna em relação aos métodos de tratamento organicistas, ou, mesmo, teriam sido condenadas ao limbo.

No entanto, o trabalho realizado por Heitor Péres na direção do maior hospital psiquiátrico do Rio de Janeiro aponta para a necessidade de uma leitura mais cuidadosa e complexa deste período, visto que ele também foi um grande incentivador destas práticas. Por essa razão, o tópico a seguir buscará compreender como a praxiterapia estava inserida no contexto da psiquiatria brasileira entre as décadas de 1940 e 1950 a partir da trajetória profissional de Heitor Péres.

\section{Praxiterapia integral: "um sistema brasileiro de assistir doentes mentais"}

Em 1938, quando era diretor substituto da DAP, Heitor Péres publicou o artigo $A$ terapêutica ocupacional: bases racionais para organisá-la(sic) nos hospitais do S.A.P.. No texto, escrito com a colaboração de Waldemiro Pires (1892-1977), então diretor da DAP, os autores propõem uma estratégia de organização do serviço de praxiterapia da CJM. Este é o primeiro trabalho em que Heitor Péres toma a praxiterapia como tema. Porém, é preciso lembrar que ele já havia tido um longo contato com esta prática, uma vez que na CJM as 
ocupações terapêuticas eram, até este momento, a principal forma de tratamento das doenças mentais.

Fundada em 1924 e inicialmente denominada Colônia de Psicopatas Homens, a CJM foi criada para sanar os problemas de superlotação nas colônias de São Bento e Conde de Mesquita, localizadas na Ilha do Governador, no Rio de Janeiro. Estas colônias agrícolas foram criadas em 1890 pelo órgão de Assistência a Alienados do Distrito Federal para receber doentes indigentes transferidos do Hospício Nacional, reservando a esta última instituição a tutela dos pacientes pensionistas (Venâncio, 2011). Quando a CJM foi inaugurada, a proposta era que recebesse prioritariamente pacientes crônicos e oferecesse tratamento por meio do trabalho agrícola e da terapêutica heterofamiliar, que consistia no incentivo à convivência dos doentes com pessoas sadias por meio da prestação de serviços domésticos aos funcionários que moravam nas terras da colônia.

No artigo referido acima, Pires e Péres (1938) sinalizam problemas no serviço de praxiterapia da CJM e apresentam uma proposta de organização deste setor, visando seu aprimoramento. Para tanto, realizam inicialmente uma explanação quanto ao uso da praxiterapia em diversos países do mundo, buscando acentuar os acertos e equívocos resultantes do uso de ocupações terapêuticas em diversas instituições psiquiátricas. Neste sentido, realizam um levantamento histórico do uso das ocupações terapêuticas pela psiquiatria internacional, destacando três fases de aplicação desta prática.

De acordo com Pires e Péres (1938), a primeira delas teria se iniciado no final do século XVIII e perdurado até o início do século XIX. Segundo os autores, esta fase seria caracterizada pela doutrina do tratamento moral, momento no qual as ocupações serviriam apenas para distrair os doentes de seus pensamentos mórbidos, sendo priorizadas as atividades agrícolas e rurais. Já na segunda fase, que vai do final do século XIX ao início do século XX (os autores deixam uma lacuna em relação ao que teria ocorrido ao longo do século XIX), as atividades agrícolas teriam perdido importância e as ocupações terapêuticas teriam se voltado para a produção de bens em oficinas e trabalhos manuais em geral. Os autores afirmam ainda que, nesta segunda fase, a terapêutica ocupacional teria passado a ser desenvolvida também em hospitais urbanos e a questão econômica (uso da mão de obra dos pacientes para suprir as necessidades da instituição) teria se tornado mais valorizada.

A terceira fase seria o período do qual os autores são contemporâneos; colocam a Alemanha, a Holanda e os Estados Unidos como países expoentes de um movimento renovador da praxiterapia. Tal fase seria marcada por um pluralismo teórico e prático 
caracterizado pela ênfase no caráter social do método terapêutico, conforme sugerem no trecho a seguir:

O doente, não é mais para os nossos dias o indivíduo que perdeu a razão e deve ser tratado e protegidos os seus bens; é uma partícula indissoluvelmente ligada ao meio, que se desarticulou da coletividade, merecendo tratamento, mas, sobretudo, preservando-se as suas reações perigosas e facilitando-lhe a readaptação social. Assim, deve o trabalho do alienado seguir as mesmas normas observadas no das coletividades sãs (Pires \& Péres, 1938, p. 79).

Os autores destacam ainda a originalidade da terapêutica ocupacional norte-americana por sua universalidade, visto que esta prática seria direcionada para atender todos os cidadãos que carecessem de amparo médico-social e não apenas os doentes mentais. A terapia ocupacional nos Estados Unidos havia se tornado um campo separado da psiquiatria desde o fim da I Guerra Mundial, quando a escassez de mão-de-obra e a necessidade de criação de programas de reabilitação fomentou o surgimento dos primeiros cursos de formação (De Carlo \& Bartalotti, 2001).

Com relação ao Brasil, Pires e Péres (1938) afirmam não ser possível tomá-lo como exemplo para explicar as três fases apresentadas. Ao descrever experiências realizadas no Rio de Janeiro, Minas Gerais, São Paulo e Pernambuco, afirmam que, nos dois primeiros estados, o que se fazia até aquele momento seria o trabalho comum, auxiliar aos serviços internos, incluindo o trabalho em lavouras e outros serviços braçais. No caso de São Paulo, ainda segundo os autores, o trabalho bem iniciado não estaria atingindo a extensão prevista. Em Pernambuco, apesar do intenso emprego da praxiterapia, estase restringiria ao trabalho agrícola, considerado por eles como reduzido e parcial. Suas críticas apontam para a falta de recursos e de sistematização no uso de ocupações terapêuticas em todas as experiências brasileiras, mesmo em Pernambuco, onde a experiência parece ter tido algum sucesso. Expõem, assim, uma preocupação com o resgate do valor terapêutico da praxiterapia no Brasil:

Estamos realmente a necessitar de uma organização definitiva, que tenha como escopo o trabalho sistemático dos doentes, visando torna-los menos pesados à economia oficial, mas antes e sobretudo, a recuperação dos mesmos à normalidade, integrandoos na comunhão da sociedade laboriosa (Pires \& Péres, 1938, p. 80). 
Após este panorama, Pires e Péres (1938) apresentam algumas diretrizes para o bom funcionamento dos serviços de praxiterapia nas instituições psiquiátricas, indicando a necessidade da presença de um técnico especializado que, como instrutor, ensinaria o pessoal encarregado a dirigir autonomamente as atividades dos doentes. Já os critérios para ser um técnico na área da praxiterapia seriam possuir conhecimentos de enfermagem psiquiátrica e conhecimento das diversas modalidades de trabalho ofertadas. Quanto às ocupações, afirmam que os trabalhos em oficinas, os trabalhos manuais e a jardinagem seriam mais adequados aos hospitais urbanos, enquanto as ocupações agro-rurais e industriais deveriam ser priorizadas nas colônias. Sugerem ainda que em todos estes estabelecimentos deveriam ser implementados o que denominam de meios complementares da terapêutica ativa, como os jogos de salão, atividades esportivas e ginástica, salas de leitura, teatro, cinema etc.

Percebe-se, assim, por meio do discurso dos autores, uma tentativa de elevar a importância da praxiterapia no campo da assistência psiquiátrica. $\mathrm{O}$ fato de ambos assumirem naquele momento posições de chefia em órgão vinculado ao Ministério da Educação e Saúde, orientando políticas públicas de abrangência nacional, possibilita inferir que o tema assumia relevância neste contexto. Para subsidiar esta conclusão, é preciso observar que há uma historiografia da psiquiatria mais recente que também aponta para uma valorização da praxiterapia pela psiquiatria brasileira neste período, mas sem, todavia, esmiuçá-la, apresentar seus propósitos e técnicas, como é a pretensão deste artigo. Facchinetti (2018), por exemplo, afirma que a praxiterapia chegou a ser considerada a modalidade psicoterápica mais importante no início da década de 1940, pois se acreditava ser possível utilizá-la para quase todos os quadros psicopatológicos. Já Braga (2015) e Venâncio (2011) afirmam que, no final dos anos 1930 e início da década de 1940, a praxiterapia havia se tornado uma das principais estratégias assistenciais do SNDM, passando a ser amplamente aplicada na CJM para além das atividades agrícolas.

Foi neste contexto de valorização desta prática que, em 1946, Heitor Péres tornou-se diretor da CJM e iniciou o processo de implantação na instituição daquilo que denominou praxiterapia integral, que consistia na criação de uma série de ocupações e serviços com o objetivo de introduzir no hospital o máximo de atividades dentre as existentes fora dele. A ideia era transformar a CJM em uma pequena cidade onde os pacientes poderiam ter acesso a trabalho e lazer.

A implantação deste programa na CJM levou Heitor Péres a ser convidado a se apresentar em eventos científicos para tratar do tema, como ocorreu durante o $V$ Congresso 
Brasileiro de Psiquiatria, Neurologia e Medicina Legal, realizado em 1948. Neste evento, duas sessões foram dedicadas à praxiterapia. De acordo com programação publicada no Jornal do Comércio, de 3 de novembro de 1948, para a primeira sessão - que pode ser denominada de "sessão de comunicação" -, onde o tema era recomendado, foram aceitos 13 trabalhos. Dentre estes, quatro versavam sobre praxiterapia: Bandas de música do Hospital de Juqueri e musicoterapia; Desenvolvimento mental e brinquedo; Uma experiência de laborterapia na Sociedade Pestalozzi do Brasil; e Uma bandinha rítmica na Sociedade Pestalozzi do Brasil. Na segunda sessão, uma mesa redonda, apresentaram-se os relatores convidados Heitor Péres, Oswaldo Domingues de Moraes (não foram encontrados dados de nascimento e morte), então chefe da Seção de Praxiterapia da CJM, e Nise da Silveira. O fato desta forma de tratamento ser tema em um importante congresso reforça, a nosso ver, a relevância da praxiterapia no campo da assistência psiquiátrica naquele momento.

No relatório geral sobre o tema apresentado por Heitor Péres, publicado no Boletim da Colônia Juliano Moreira, em 1949, o relator explicita quais seriam, para ele, os benefícios da praxiterapia integral, quais sejam: 1) medida profilática no tratamento das doenças mentais;2) atividade necessária à transformação do espaço hospitalar, que, do seu ponto de vista, é muitas vezes causa da deterioração mental em razão da ação deformadora do ambiente; 3) instrumento da atuação médica diante das coletividades. Estes pontos reforçam a ideia de que os tratamentos organicistas, apesar de muito utilizados, não se tornaram exclusivos na CJM durante a gestão de Heitor Péres. Por outro lado, insere também uma perspectiva em que a praxiterapia funcionaria como medida preventiva, necessária contra o processo de cronificação dos pacientes nos hospitais psiquiátricos.

No mesmo relatório, Heitor Péres demonstra também uma preocupação com a ineficácia daqueles tratamentos de caráter organicista, de ação individualizada. Ao perceber a incapacidade dos médicos de tratar a massa de pacientes, ele enxerga a praxiterapia como uma alternativa eficiente aos métodos de tratamentos somáticos. Crê, assim, que a praxiterapia aplicada de forma sistemática e organizada poderia até mesmo substituir aquelas outras formas de tratamento. Portanto, para ele, a cura ao nível da coletividade proporcionada pela praxiterapia integral justificaria sua melhor eficácia em relação aos outros métodos de tratamento oferecidos pelas instituições psiquiátricas. De acordo com Péres (1949):

A grande massa de crônicos chega à incurabilidade através desse conceito errôneo de se fazer da terapêutica ocupacional individual o fulcro da assistência. O que se vê? Mesmo com os métodos modernos de tratamento - os ditos métodos somáticos - a 
capacidade curativa do médico - que quer curar um por um ou que tem de assim fazer, limitada, humanamente limitada, curando pouco, pois a massa é enorme e a aplicação individual, intensiva, requerida pela gravidade da doença, deixa que lhe escape a melhor fase de curar (Péres, 1949, p. 4 [grifo do autor]).

O que fica evidente também no relatório citado acima é uma crítica feita à terapêutica ativa, método criado pelo alemão Hermann Simon (1867-1947), que consistia em oferecer aos pacientes atividades em grau de dificuldade crescente, método amplamente utilizado por Ulisses Pernambucano (1892-1943) ao longo da década de 1930 (Medeiros, 2001). Segundo Péres (1949), esta técnica seria inadequada, pois se restringiria a oferecer apenas trabalho aos pacientes, levando excessivamente em conta características individuais na indicação das atividades. De acordo com ele, a praxiterapia integral, por outro lado, deveria estar orientada para as massas, para as coletividades.

Sua ideia seria fazer de cada setor do hospital uma comunidade organizada, dotada de um espírito ativo e normalizador. Seu método valorizava o caráter ressocializante das ocupações com foco na reintegração dos pacientes na vida em comunidade. Neste sentido, Heitor Péres chega a afirmar que a praxiterapia integral seria uma técnica terapêutica que "racionalmente considera úteis e aproveitáveis todos os enfermos, sem as limitações doutrinárias ou teóricas frias dos prognósticos clínicos, dos rótulos nosográficos, que configuram doenças e não homens" (Péres, 1949, p. 5). Por essa razão, a praxiterapia deveria estimular não só as atividades produtivas realizadas em oficinas, mas também aquelas voltadas para o lazer e a socialização.

Ainda segundo o relatório, a praxiterapia integral estaria obtendo bons resultados na CJM e poderia vir a se tornar um "sistema brasileiro de assistir doentes mentais" (Peres, 1949, p. 12). Esta afirmação de Heitor Péres, na época diretor da maior instituição psiquiátrica do Distrito Federal, nos possibilita questionar, mais uma vez, o discurso de que a praxiterapia era vista com maus olhos pela classe médica ou que se tratava de método subalterno em relação aos tratamentos de base organicista. Ao contrário, o uso da praxiterapia parece ter sido bastante estimulado por Heitor Péres nas funções que ocupou em órgãos voltados para a assistência psiquiátrica, sendo inclusive incrementado durante a sua gestão na CJM.

Assim, sobre as atividades praxiterápicas desenvolvidas na CJM sob a direção de Heitor Péres, além do trabalho agrícola e demais oficinas voltadas para a produção de bens para consumo da própria instituição, destacam-se aquelas com fins recreativos, artísticos e culturais. De acordo com informações levantadas no Boletim da Colônia Juliano Moreira, 
dentre elas estavam, entre outras, atividades envolvendo rádio, cinema, teatro, leitura e pintura (Péres, 1949). Ainda segundo informações encontradas no periódico, a maior parte destas atividades foi realmente implementada na gestão de Heitor Péres.

Na edição de agosto, setembro e outubro de 1949, por exemplo, é transcrita a fala de um paciente, após uma sessão de cinema, onde este afirma que a atividade agradaria e alegraria os doentes. Em outro número do Boletim da Colônia Juliano Moreira, de 1951, um informe anunciava a instalação definitiva do sistema de amplificação sonora e alto falantes, concluída em 1950, o que proporcionou a expansão de um sistema de retransmissão da Rádio Nacional com "música ligeira" pela manhã e "música fina" na parte da tarde. O sistema de radiodifusão funcionava desde 1948 na CJM e, agora, passava a atender toda a sua área. Os números do Boletim da Colônia Juliano Moreira apresentam ainda fotografias das equipes esportivas formadas por pacientes, assim como das salas de jogos, sala de leitura e sala de piano da CJM.

O uso da música como instrumento terapêutico parece ter sido também uma das estratégias da praxiterapia integral implementada na CJM não só por meio da rádio, mas também pela criação de oficinas musicais. Ainda não possuímos dados suficientes para esclarecer como essas atividades eram desenvolvidas e quantos pacientes eram atendidos, porém, existem indícios de que, além da oficina de piano, foram criadas neste período outras oficinas envolvendo a música. Por exemplo, em um informe sobre a realização da festa de Natal da CJM publicado no Jornal do Brasil em 21 de dezembro 1954, a programação da cerimônia incluía recital de música, de canto, além de show e declamação a cargo de pacientes e artistas amadores.

A menção às atividades oferecidas aos pacientes da CJM em jornais demonstra que o esforço de Heitor Péres para a divulgação da praxiterapia enquanto método de tratamento das doenças mentais não se restringiu ao meio médico. A maneira como a praxiterapia começou a ser divulgada nos jornais reforça a ideia de que esta forma de tratamento estava sendo propagada por ele como um método inovador de tratamento da loucura nas instituições psiquiátricas. Ainda como desdobramento do $V$ Congresso Brasileiro de Psiquiatria, Neurologia e Medicina Legal, alguns jornais divulgaram as mudanças realizadas na CJM para a ampliação das atividades praxiterápicas. O Jornal do Brasil de 11 de maio de 1949, por exemplo, informa:

Tem o diretor dessa instituição ideias próprias e experiências pessoais sobre o assunto. Com as modificações que lhe pareceu conveniente introduzir, vem a direção da 
Colônia Juliano Moreira orientando a prática daquele método, de forma a transformar o ambiente dos doentes que, se assim se pode dizer, vivem uma vida normal (Jornal do Brasil, 11 de maio de 1949, p. 5).

Ao longo da década de 1950, Heitor Péres continuou sendo uma referência no Rio de Janeiro na área da praxiterapia. Durante o I Simpósio de Terapêutica Ocupacional, realizado no Rio de Janeiro, em 1956, apresentou a conferência Esforço histórico de praxiterapia no Brasil em uma mesa realizada na Faculdade Nacional de Filosofia. Da mesma mesa participaram Nise da Silveira, com a conferência A terapêutica ocupacional no Centro Psiquiátrico Nacional e Denis Malta Ferraz (não foram encontrados dados de nascimento e morte), com a conferência Ocupação terapêutica nos estabelecimentos psiquiátricos infantis. Sua importância no processo de transformação da CJM, especialmente pela sua dedicação no aprimoramento da praxiterapia, é evidenciada em reportagem do jornal Tribuna da Imprensa de 2 de junho de 1959, quando já havia deixado a direção da instituição. Diante da constatação da precariedade dos serviços oferecidos aos pacientes da instituição, a matéria do jornal afirma:

A cidade dos insanos, tendo perdido em aspectos a sua antiga característica humanização dos métodos de assistir e tratar o enfermo - apresenta-se aos olhos do leigo visitante como um depósito de loucos. Todavia, a luta ali travada para recompor o esquema 'Heitor Péres' já está dando resultados positivos (Tribuna da Imprensa, 2 de junho de 1959).

Após este período, parece ter ocorrido um novo esforço de reorganização da praxiterapia por meio do incentivo à pesquisa. Um informe do jornal Correio da Manhã, de 23 de julho de 1959, anuncia a realização de um seminário sobre praxiterapia na CJM organizado pelo Centro Brasileiro de Estudos Psiquiátricos, e outro informe do mesmo jornal, de 11 de agosto de 1959, menciona a inauguração do Instituto Ministro Mário Pinotti nas dependências da CJM, que compreendia, entre outros serviços, um Setor de Pesquisas Praxiterápicas. 


\section{Praxiterapia e atividades artísticas na CJM}

Das atividades praxiterápicas desenvolvidas na CJM sob a direção de Heitor Péres, a de que se tem mais informações até o momento é a oficina de pintura, denominada Colmeia de Pintores - parte dos trabalhos produzidos nesta oficina encontram-se preservados ainda hoje pelo Museu Bispo do Rosário Arte Contemporânea (mBRAC), no IMASJM. Isto porque algumas obras deste acervo estiveram presentes na Exposição de Arte Psicopatológica, que ocorreu durante o I Congresso de Psiquiatria de Paris, em 1950. Os trabalhos foram expostos ao lado de outros enviados pelo CPN, pelo Hospício do Juquery e por diversas instituições psiquiátricas de todo o mundo.

No mesmo ano, pouco antes da exposição de Paris, inaugurou-se em maio, na própria CJM, a Primeira Exposição de Pintura e Arte Feminina Aplicada. Inicialmente programada para ir até julho, a mostra logo viria a se tornar permanente. Localizada na sala de visitantes da CJM, exibia 98 quadros de cinco pacientes, todos participantes da Colmeia de Pintores. A exposição reunia ainda outros objetos classificados na categoria "arte feminina aplicada", oriundos de oficinas de praxiterapia do Núcleo Teixeira Brandão, que abrigava mulheres. Dois anos antes, haviam sido iniciadas nesta unidade da CJM oficinas de bordado, ornamentação de cerâmica, trabalho de agulha, flores artificiais e adornos (Péres, 1949).

A abertura da exposição contou com a presença do Ministro interino da Educação e Saúde, Eduardo Rios (não foram encontrados dados de nascimento e morte), e teve a cobertura de jornais. O jornal Correio da Manhã de 27 de maio de 1950, em coluna com o título Na Colônia Juliano Moreira - Terapêutica moderna baseada na expansão artística, assinalou o espetáculo cromático das pinturas expostas. Já o jornal A Noite, de 29 de junho de 1950, divulgou a mostra dizendo ser ela de indiscutível interesse artístico e científico.

A participação das pinturas da CJM na exposição de Paris também teve boa recepção nos jornais brasileiros. Em artigo do Jornal do Brasil de 22 de Outubro de 1950, por exemplo, as atividades artísticas realizadas na instituição foram apresentadas da seguinte forma:

Pôde, assim, o mundo civilizado ficar sabendo que no Brasil, o tratamento dos psicopatas já se faz pelos métodos mais modernos e que a terapia ocupacional adaptada ao nosso meio sob o nome de praxiterapia integral, vem dando resultados muito animadores (Jornal do Brasil, 22 de outubro de 1950, p. 5). 
A metodologia utilizada nas oficinas envolvendo atividades artísticas e explicitada no catálogo da exposição realizada na CJM demonstra uma tendência ao trabalho orientado e padronizado. Nele, fica explícito que na Colmeia de Pintores os trabalhos eram produzidos de forma dirigida, com forte incentivo à reprodução, à cópia e à produção plástica de caráter figurativo. Sobre o paciente Hyacinto, por exemplo, o catálogo afirma que "neste enfermo a orientação arteterápica mais acertada, tem sido a de leva-lo a copiar 'd'aprésnature', estimulando melhor contato com o meio, evitando a composição espontânea que lhe acentua a dissociação e, portanto, o desajustamento psíquico" (Péres, 1950b, p. 6). Quanto a outro paciente, o catálogo indica que "terapeuticamente vai sendo conduzido o mais possível para o plano objetivo: cópias, ampliações, temas sugeridos, etc" (Péres, 1950b, p. 7).

Esta proposta arteterapêutica da CJM distingue-se daquelas realizadas no Brasil por Nise da Silveira e Osório César. Isso porque, tanto na STO quanto na Seção de Pintura do Juquery, a livre expressão foi fortemente estimulada. Segundo Melo (2009), este método foi implementado na STO mesmo naqueles setores em que as atividades artísticas não se faziam presentes, pois se compreendia que o desenvolvimento da espontaneidade era a função básica da terapia ocupacional. Já Osório César, que além de psiquiatra era crítico de arte e tinha, portanto, grande interesse no potencial artístico dos seus pacientes, afirmou em artigo de 1924 que "a arte para ser genial tem que ser livre" (César, 2007, p. 123). Foi com esta mesma perspectiva que assumiu, em 1950, a coordenação da Seção de Pintura do Juquery.

O trabalho dirigido na Colmeia de Pintores tinha a função de reorganizar as funções psíquicas do doente. Sendo assim, havia um entendimento de que, quanto maior a capacidade do paciente de copiar e reproduzir figuras e paisagens, mais próximo este estaria do estado de “normalidade". Um artigo de Heitor Péres, intitulado O critério psiquiátrico na interpretação da pintura modernista e publicado no Boletim da Colônia Juliano Moreira, em 1952, auxilia a compreender sua visão quanto ao que entende por normalidade na arte. Neste texto, mesmo reconhecendo o valor do trabalho realizado pela vanguarda artística da época, para quem a pintura acadêmica e figurativa estaria ultrapassada, ele é categórico em sua interpretação deste movimento: "nem por isso deixa de ser anormal, flagrante, aos olhos de qualquer especialista, nas suas inúmeras, inequívocas, manifestações desarmônicas" (Péres, 1952).

Heitor Péres acreditava ainda que os desenhos e pinturas produzidos na Colmeia de Pintores poderiam oferecer ao psiquiatra material para fins de diagnóstico do paciente. Em uma entrevista reproduzida em seu livro, quando questionado sobre o potencial curativo da arte, ele afirma: "ajuda pelo menos, e serve-nos como meio de estudo para penetrarmos a intimidade da enfermidade mental" (Péres, 1950a, p. 92). O mesmo entendimento quanto ao 
uso diagnóstico da produção artística de pacientes é confirmado em um relatório sobre a exposição de 1950, publicado no Boletim da Colônia Juliano Moreira. Neste documento, onde se reproduz o discurso de Heitor Péres na inauguração da exposição, o mesmo afirma que a arteterapia serviria "como instrumento de penetração à intimidade do enfermo; tal qual um revelador químico" (Brasil, 1951, p. 12). A comparação contida nesta frase é um bom exemplo de como em seu pensamento seria possível estabelecer paralelos entre as teorias organicistas e o tratamento por meio das ocupações terapêuticas.

\section{Considerações Finais}

As conclusões desse estudo sobre o trabalho realizado pelo psiquiatra Heitor Péres na CJM sugerem o emprego paralelo de teorias organicistas e métodos de tratamentos com base nas ocupações terapêuticas em sua prática profissional. Sua trajetória ajuda a complexificar a leitura histórica que se tem feito da psiquiatria brasileira das décadas de 1940 e 1950, assim como auxilia a desmistificar a ideia de que a praxiterapia era percebida neste contexto como um método de tratamento inferior àqueles de base organicista.

Fugindo desta leitura reducionista, parece-nos possível considerar que, possivelmente, assim como pode ser observado na experiência de Heitor Péres, outros psiquiatras que presenciaram o surgimento de modernos tratamentos para as doenças mentais na década de 1930, e cujos conhecimentos anatomo-fisiológicos pareciam dar conta de sua aplicação e eficácia, não abriram mão, em suas análises científicas, dos fatores psicossociais e psicodinâmicos que poderiam determinar e tratar as doenças mentais.

Deste modo, através deste levantamento, pôde-se verificar que o meio psiquiátrico brasileiro nas décadas de 1940 e 1950 talvez estivesse mais permeável do que se imagina a outras formas de lidar e tratar a loucura, seja por meio da praxiterapia, de modo geral, seja pelo uso da arteterapia, especificamente. O vínculo formal de Heitor Péres com instituições e entidades ligadas à psiquiatria ao longo de toda a sua carreira, assim como as posições de chefia que assumiu em muitas destas instituições, inclusive sendo indicado ao cargo de direção da CJM, sugere que suas ideias eram respeitadas pelos seus pares, e, consequentemente, ampara a hipótese levantada aqui de que a praxiterapia, tão divulgada por ele, tinha seu lugar - não inferior - no interior das práticas psiquiátricas.

Por fim, estas informações trazem outra perspectiva para o uso da arteterapia nas instituições psiquiátricas públicas do Distrito Federal neste período, descentralizando a memória, insistentemente reduzida à experiência de Nise da Silveira no CPN, e ampliando a 
visão sobre o assunto. Ao se fazer isto, torna-se possível colocar uma nova luz sobre o uso de ocupações terapêuticas envolvendo atividades artísticas desenvolvidas no Brasil nas décadas de 1940 e 1950. No caso de Heitor Péres, parece que, apesar de ter demonstrado um grande interesse pela psiquiatria organicista, não deixou de vislumbrar a eficácia e os benefícios da praxiterapia e da arteterapia no tratamento das doenças mentais.

\section{Referências}

A Colônia Juliano Moreira. (1950, Junho 29). A Noite, pp. 8. Recuperado de http://memoria.bn.br/pdf/348970/per348970_1950_13525.pdf

A pintura na Colônia (1959, Junho 2). Tribuna da Imprensa, pp. 10. Recuperado de http://memoria.bn.br/DocReader/154083_01/47728

Braga, A. L. C. (2015). A assistência psiquiátrica da Colônia Juliano Moreira no governo JK. In A. T. Venancio \& G. F. Potengy (Orgs.), O asilo e a cidade: Histórias da Colônia Juliano Moreira (pp. 253-272). Rio de Janeiro: Garamond.

Bragança: notável pintor brasileiro. (1950, Outubro 22). Jornal do Brasil, pp. 5. Recuperado de http://memoria.bn.br/DocReader/030015_07/6501

Brasil. Ministério da Educação e Saúde. (1949). Boletim da Colônia Juliano Moreira, 4(1-3), s.p.

Brasil. Ministério da Educação e Saúde. (1951). Boletim da Colônia Juliano Moreira, 5(1), 12.

César, O. (2007). A arte primitiva nos alienados (1924): Manifestação escultórica com caráter simbólico feiticista num caso de síndrome paranoide. Revista Latinoamericana de Psicopatologia Fundamental, 10(1), 118-130. doi:10.1590/1415-47142007001011

Colônia Juliano Moreira. (1949, Maio 11). Jornal do Brasil, pp. 5. Recuperado de http://memoria.bn.br/DocReader/030015_06/59927

Costa, J. F. (2006). História da Psiquiatria no Brasil: Um corte ideológico. Rio de Janeiro: Garamond.

De Carlo, M. M., \& Bartalotti, C. C. (2001). Caminhos da Terapia Ocupacional. In M. M. De Carlo \& C. C. Bartalotti (Orgs.), Terapia Ocupacional no Brasil: Fundamentos e perspectivas (pp. 19-40). São Paulo: Plexus Editora.

Facchinetti, C. (2018). História das psicoterapias e da psicanálise no Brasil: O caso do Rio de Janeiro. Estudos e pesquisas em psicologia, 18(4), 1106-1117. Recuperado de https://www.e-publicacoes.uerj.br/index.php/revispsi/article/view/42225/29296 
Hoje na Colônia Juliano Moreira o Ministro da Saúde. (1959, Agosto 11). Correio da Manhã, pp. 2. Recuperado de http://memoria.bn.br/pdf/089842/per089842_1959_20360.pdf

Mathias, C. M. (2017). O pavilhão de observação na psiquiatria do Distrito Federal: A gestão de Henrique Roxo (1921-1945) (Dissertação de mestrado). Casa de Oswaldo Cruz, FIOCRUZ, Rio de Janeiro, RJ, Brasil. Recuperado de https://www.arca.fiocruz.br/handle/icict/24002

Medeiros, J. A. (2001). Ulisses Pernambucano. Rio de Janeiro: Imago, CFP.

Melo, W. (2001). Nise da Silveira. Rio de Janeiro: Imago.

Melo, W. (2009). Nise da Silveira e o campo da Saúde Mental (1944-1952): Contribuições, embates e transformações. Mnemosine, 5(2), 30-52. Recuperado de https://www.epublicacoes.uerj.br/index.php/mnemosine/article/download/41432/pdf_158

Muñoz, P. F. N. (2015). À luz do biológico: Psiquiatria, neurologia e eugenia nas relações Brasil-Alemanha (1900-1942) (Dissertação de mestrado). Casa de Oswaldo Cruz, FIOCRUZ, Rio de Janeiro, RJ, Brasil. Recuperado de https://www.arca.fiocruz.br/handle/icict/17721

Na Colônia Juliano Moreira. (1954, Dezembro 21). Jornal do Brasil, pp. 9. Recuperado de http://memoria.bn.br/DocReader/docreader.aspx?bib=030015_07\&pasta=ano\%20195 \&pesq=Juliano\%20Moreira

Na Colônia Juliano Moreira, terapêutica moderna baseada na expansão artística. (1950, Maio 27). Correio da Manhã, pp. 2. Recuperado de http://memoria.bn.br/pdf/089842/per089842_1950_17544.pdf

Péres, H. (1949). Praxiterapia integral. Boletim da Colônia Juliano Moreira, 8-9(1-12), 4-12.

Péres, H. (1950a). Narrativas de um psiquiatra. Rio de Janeiro: A. Coelho Branco.

Péres, H. (1950b). Primeira exposição de pintura e arte feminina aplicada da Colônia Juliano Moreira [catálogo de exposição]. Rio de Janeiro: Colônia Juliano Moreira.

Péres, H. (1952). O critério psiquiátrico na interpretação da pintura modernista. Boletim da Colônia Juliano Moreira, 6, s.p.

Pires, W., \& Péres, H. (1938). A terapêutica ocupacional: Bases racionais para organisá-la (sic) nos hospitais do S.A.P. Archivos brasileiros de medicina, 28, 79-80.

Praxiterapia integral. (1949, Junho 24). Jornal do Brasil, pp. 5. Recuperado de http://memoria.bn.br/DocReader/docreader.aspx?bib=030015_06\&pasta=ano\%20194 $\&$ pesq=Praxiterapia\%20integral

Seminário de praxiterapia. (1959, Julho 23). Correio da Manhã, 1 Caderno, pp. 11. Recuperado de http://memoria.bn.br/pdf/089842/per089842_1959_20344.pdf 
Silveira, N. (1992). O mundo das imagens. Rio de Janeiro: Editora Ática.

V Congresso Brasileiro de Psiquiatria, Neurologia e Medicina Legal. (1948, novembro 3). Jornal do Comércio, pp. $3 . \quad$ Recuperado de http://memoria.bn.br/docreader/DocReader.aspx?bib=364568_13\&pagfis=31854

Venancio, A. T. (2011). Da colônia agrícola ao hospital-colônia: Configurações para a assistência psiquiátrica no Brasil na primeira metade do século XX. História, Ciências, Saúde - manguinhos, 18(1), 35-52. doi:10.1590/S0104-59702011000500003

\section{Endereço para correspondência}

\section{João Henrique Queiroz de Araújo}

Rua Agenor Moreira, 97 casa 101, Andaraí, Rio de Janeiro - RJ, Brasil. CEP 20541-130

Endereço eletrônico: joaohenrique.qa@gmail.com

\section{Ana Maria Jacó-Vilela}

Laboratório de História e Memória da Psicologia Clio-Psyché - UERJ

Rua São Francisco Xavier, 524, Maracanã, Rio de Janeiro - RJ, Brasil. CEP 20550-900

Endereço eletrônico: jaco.ana@gmail.com

Recebido em: 09/01/2020

Reformulado em: 19/01/2020

Aceito em: 22/01/2020

\section{Notas}

* Doutorando do Programa de Pós-Graduação em Psicologia Social da Universidade do Estado do Rio de Janeiro.

** Professora da Universidade do Estado do Rio de Janeiro e Coordenadora do Laboratório de História e Memória da Psicologia Clio-Psyché.

Financiamento: A pesquisa relatada no manuscrito foi financiada pela bolsa de doutorado do primeiro autor (CAPES).

Este artigo de revista Estudos e Pesquisas em Psicologia é licenciado sob uma Licença Creative Commons Atribuição-Não Comercial 3.0 Não Adaptada. 